\title{
Glaucoma and vasospasm
}

\author{
David C Broadway, Stephen M Drance
}

\begin{abstract}
Aims/background-To study the vasoactivity of glaucoma patients with four previously described and distinct disc appearances potentially representative of primary open angle glaucoma subgroups. Methods-Patients with pure examples of four glaucomatous optic disc types-focal ischaemic, myopic glaucomatous, senile sclerotic, and those with generalised cup enlargement, were selected. A detailed ophthalmic, systemic, drug, and smoking history was taken from the patients who, in addition, underwent assessment of peripheral vasospasm with a laser Doppler flowmeter. Differences between the groups were evaluated using an analysis of variance, Student's $t$ test, Pearson's $\chi^{2}$ test, Fisher's exact test together with Spearman's and Pearson's correlation tests.
\end{abstract}

Results-38 patients with focal ischaemic, 37 with myopic glaucomatous, 24 with senile sclerotic, and 24 with discs characterised by generalised cup enlargement met the selection criteria. The group of patients with focal ischaemic discs contained more women (66\% versus $32 \%-50 \%$ in the other three groups; $p=0.01$ ) and had a higher prevalence of vasospasm (63\% versus $25 \%-49 \%$; $=0.01)$, migraine $(32 \%$ versus $8 \%-19 \% ; p=0.02)$, and cold extremities $\quad(66 \%$ versus $17 \%-30 \%$; $\mathbf{p}=0.00003)$. The group of patients with senile sclerotic discs had a higher prevalence of systemic cardiovascular disease (58\% versus $21 \%-30 \%$ in the other three groups; $p=0.01)$ and thyroid disease $(21 \%$ cf $0 \%-8 \% ; p=0.01$ ) and although their mean age was greater ( 76 years cf 55-65 years; $p<0.00001)$ the findings were independent of age. Smoking was unrelated to optic disc type.

Department of

Ophthalmology,

University of British

Columbia, Vancouver,

Canada

D C Broadway

S M Drance

Correspondence to:

Dr David Broadway,

Glaucoma Service, West

Norwich Hospital,

Bowthorpe Road, Norfolk, NR2 3TU.

Accepted for publication 3 February 1998 simple assessment as to whether a glaucoma patient suffers from colder extremities than average appeared to be better at distinguishing the focal ischaemic type of glaucoma than the more complex determination of vasospasm using the laser Doppler flowmeter.

(Br F Ophthalmol 1998;82:862-870)

The aetiology of open angle glaucoma is almost certainly multifactorial ${ }^{12}$ and numerous potential risk factors for development of the disease, in addition to intraocular pressure (IOP), have been identified. ${ }^{3-11}$ Cardiovascular disease in particular has been identified as a potential risk factor in the development of the condition, especially when IOP appears to have been normal. ${ }^{912-17}$ Specific cardiovascular risk factors previously reported include systemic hypertension ${ }^{718}$ or hypotension, ${ }^{19-21}$ a previous haemodynamic crisis, ${ }^{22}{ }^{23}$ increased blood viscosity, ${ }^{24}$ and diabetes. ${ }^{72} 25$ In addition, migrain ${ }^{26} 27$ and other diseases associated with vasospasm ${ }^{28-34}$ have been identified as potential risk factors for the development of low (normal) tension glaucoma. In spite of known associations between cigarette smoking and cardiovascular disease, including vasospasm, ${ }^{35}$ there are only a few studies that have reported a possible connection between smoking and glaucoma. ${ }^{76} 37$

The division of glaucoma patients into high and normal tension subgroups on the basis of a single level of IOP, is likely to be artificial with respect to aetiology. It is reasonable, therefore, to expect a proportion of patients with IOPs above $21 \mathrm{~mm} \mathrm{Hg}$ to share a similar pathogenic mechanism to those with IOPs below $21 \mathrm{~mm}$ $\mathrm{Hg}$, although in the former group IOP is more likely to exert a greater influence. In previous studies performed in our department, glaucoma patients with four specific optic disc appearances were studied and differences were identified in their demographic characteristics, prevalence of certain risk factors, and the pattern of visual field damage. ${ }^{38} 39$ The patients studied included a proportion whose IOP had never been recorded above $21 \mathrm{~mm} \mathrm{Hg}$. Patients with senile sclerotic disc appearance were found to have a greater prevalence of cardiovascular disease and more circulatory abnormalities in their retrobulbar vessels in comparison with the other groups. Patients with focal ischaemic optic disc appearance were found to suffer from migraine 2.5 times more commonly than patients in the other groups. The aim of the present study was to further 


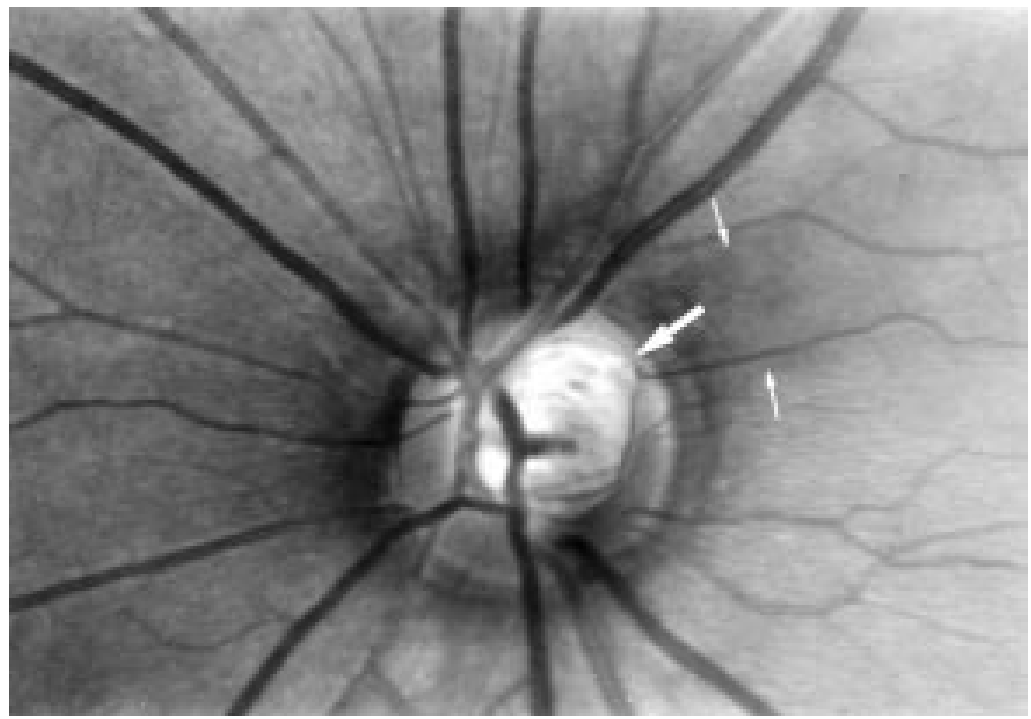

Figure 1 A classic type 1, focal ischaemic glaucomatous optic disc. There is localised superotemporal loss of neuroretinal rim tissue (large arrow) and an associated retinal nerve fibre layer defect (between the small arrows).

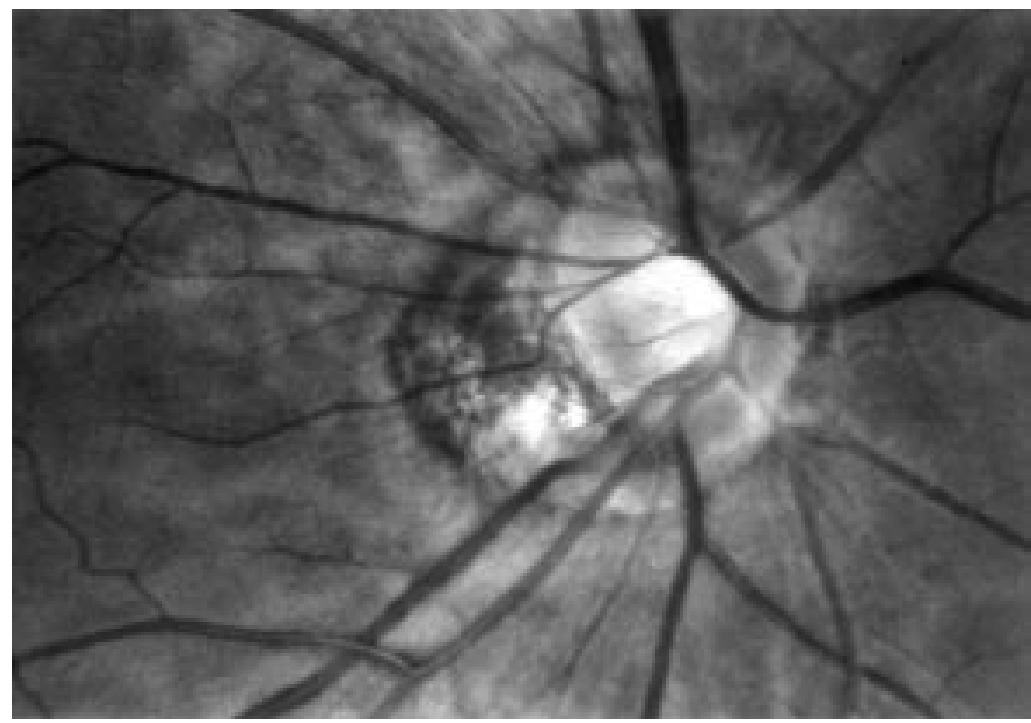

Figure 2 A classic type 2, myopic glaucomatous optic disc. The disc is tilted, has a large temporal crescent of peripapillary atrophy and thinning of both superior and inferior neuroretinal rim tissue.

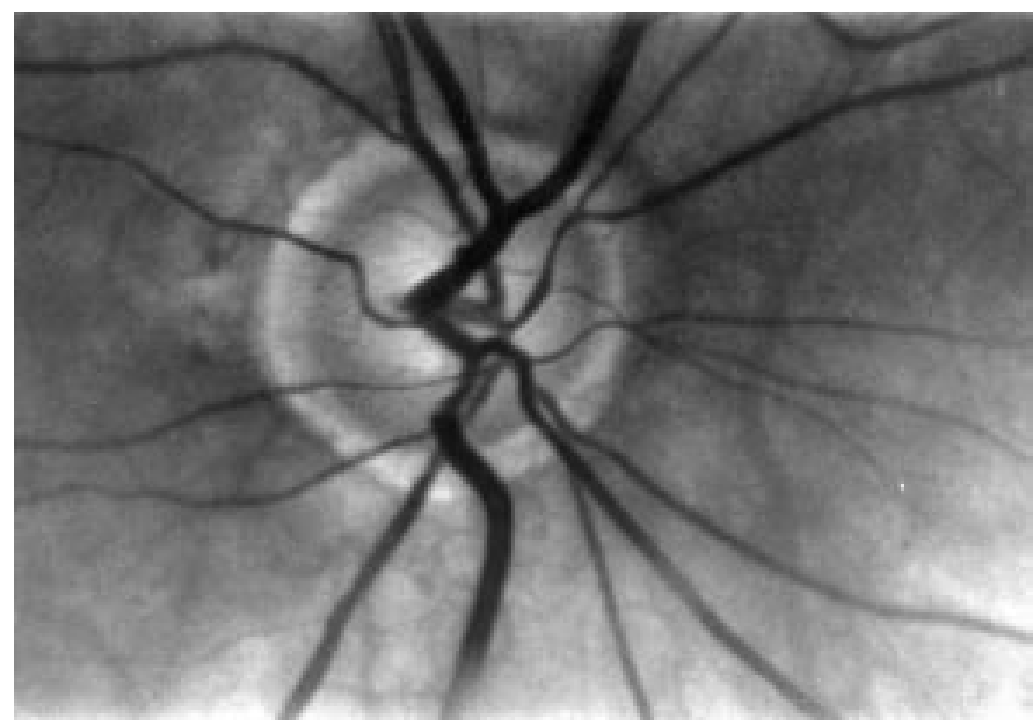

Figure 3 A classic type 3, senile sclerotic optic disc. The disc has a shallow, saucerised cup with gently sloping sides and a ring of surrounding peripapillary atrophy. investigate aspects of cardiovascular disease and vasoactivity in a group of patients belonging to the four previously described glaucomatous subgroups, selected irrespective of IOP.

\section{Patients and methods}

Stereo optic disc photographs of 1870 subjects with glaucoma or suspicion of glaucoma were reviewed separately and in a masked fashion by both authors. The photographs were those obtained from individuals seen in the glaucoma section of the Department of Ophthalmology, University of British Columbia as part of a routine consultation. An attempt was made to classify each optic disc as having one of the following four types of glaucomatous appearance:

(1) Focal ischaemic: a disc with localised tissue loss (polar notching) within the superior and/or inferior pole and an otherwise relatively intact neuroretinal rim (Fig 1). In many cases the notch was associated with a small area of peripapillary atrophy or choroidal sclerosis (fundus tessellation).

(2) Myopic glaucomatous: a tilted (obliquely implanted) disc with a shallow appearance, a myopic temporal crescent of peripapillary atrophy and additional evidence of glaucomatous damage such as thinning of the superior and/or inferior neuroretinal rim (Fig 2), in the absence of degenerative myopia. Refractive error was not taken into account in the definition of this or any disc type.

(3) Senile sclerotic: a disc with a saucerised, shallow cup and gently sloping sides, a "moth eaten" appearance, and peripapillary atrophy or choroidal sclerosis surrounding the majority of the nerve (Fig 3).

(4) Glaucomatous with generalised enlargement of the optic cup: a disc characterised by a uniformly enlarged, round cup, and no localised thinning of the neuroretinal rim (Fig 4).

The majority of optic discs were nonclassifiable (1747) and included those with a healthy looking appearance or advanced glaucomatous damage which precluded secure group classification (515), mixtures of more than one disc type (1204), degenerative myopia (3), or poor photographic quality (25). When there was any non-agreement in disc classification between the two observers the patient was excluded from the study.

In order to determine the observer errors in classification, 50 of the selected disc photographs (picked at random) were independently reclassified by both authors and the results compared with the original classification as defined by their combined decision. Agreements were 96\% (DCB) and 94\% (SMD). Following selection of the subjects on the basis of their disc photographs the following information was collated from their clinical charts: age, sex, race, ophthalmic data including family history of glaucoma, visual acuity, visual field data, highest recorded IOP measured by applanation tonometry (untreated) and the mean of the three highest recorded IOPs (treated/untreated), systemic diagnoses 


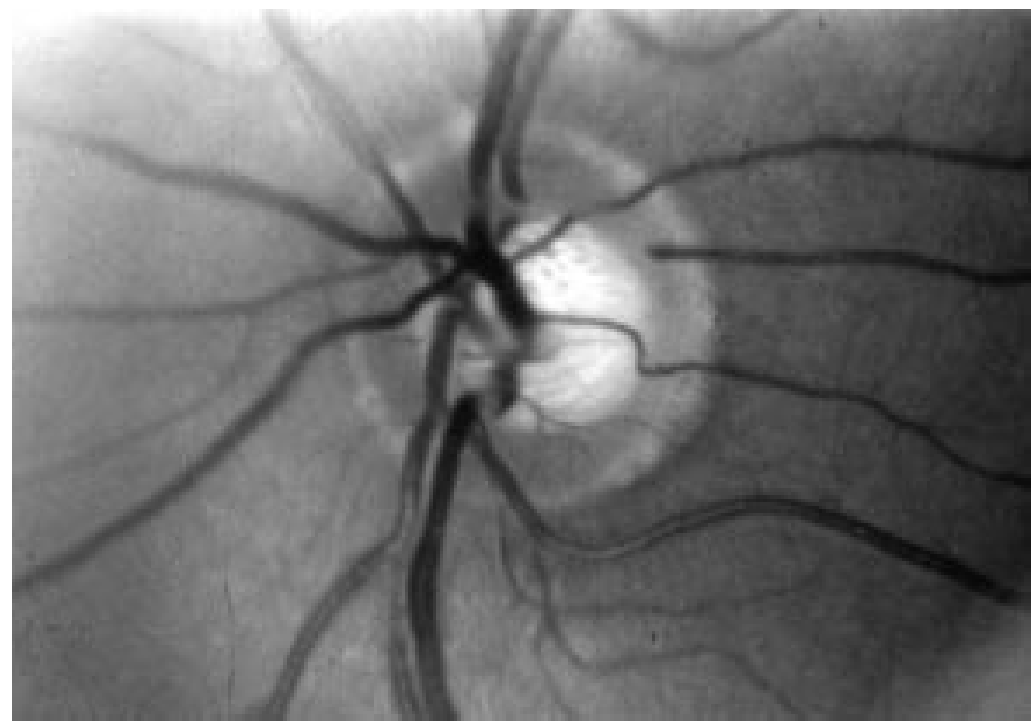

Figure 4 A classic type 4 optic disc with generalised cup enlargement. The cup is uniformly enlarged with no localised areas of neuroretinal rim tissue loss.

(migraine, cold hands/feet, hypertension, ischaemic heart disease, cerebral ischaemic disease, haemodynamic crisis, diabetes, thyroid disease), drug, and smoking history. The demographic data are collected routinely in our department, but when data were missing from a chart the patient was contacted and either reinterviewed or examined. Patients were defined as suffering from migrainous headaches if they satisfied two of the following: hemicranial distribution, association with visual effects (for example, wavy vision, scotomata), photophobia, nausea, and/or a positive response to antimigrainous therapy.

Patients with secondary glaucoma, additional ocular pathology that could be associated with optic nerve damage, and/or visual field loss were excluded from the study. Pseudophakic eyes were not excluded when the glaucomatous process predated cataract extraction. The level of IOP was not considered in the selection of eyes for the study. Each selected patient had undergone automated visual field analysis (Humphrey program 30-2; Humphrey Instruments Inc, San Leandro, CA, USA). The visual fields were classified on the basis of the Humphrey age corrected pattern standard deviation analysis. A glaucomatous visual field defect was defined as a 30-2 visual field with (a) at least three adjacent test points having a deviation greater than or equal to $5 \mathrm{~dB}$ lower than the age matched controls, with one point greater than $10 \mathrm{~dB}$ lower, (b) at least two adjacent test points greater than or equal to 10 $\mathrm{dB}$ lower, or (c) at least three adjacent points, greater than or equal to $5 \mathrm{~dB}$ lower, abutting the nasal horizontal meridian. If a visual field was considered to demonstrate artefactual defects the eye was excluded from the study. In addition, each selected patient had undergone a laser Doppler flowmeter (PF2, Perimed, Stockholm, Sweden) assessment of peripheral vasospasm. The flowmeter probe was attached to the skin overlying the terminal phalanx of the middle finger of the right hand and the patient was seated comfortably. A baseline blood pressure was recorded. Finger flow in arbitrary flow units was recorded (with the hand at the level of the heart) until a steady baseline reading was achieved. After this, the right hand was immersed in warm $\left(41^{\circ} \mathrm{C}\right)$ water for 2 minutes and then wrapped in a towel until a maximum flow was reached. At this point the hand was placed in iced $\left(4^{\circ} \mathrm{C}\right)$ water for 10 seconds after which flow was measured for several minutes. Blood pressure was recorded for a second time and the flow measurements ignored if there had been significant $(10 \mathrm{~mm} \mathrm{Hg})$ change in the mean blood pressure. A patient was arbitrarily defined as vasospastic if the ratio of maximum flow to after-cold flow was greater than 7 . In addition, each patient was allocated a "vasospasm score" (0-3) receiving a single unit for a vasospastic response to temperature change, suffering migraine, and/or reporting cold extremities. In all cases the history for cold extremities and migraine was obtained before the patient knew whether they were vasospastic to temperature change. Each patient was allocated an "overall cardiovascular disease score" (0-5), scoring a point for hypertension, ischaemic heart disease, cerebral ischaemic disease, diabetes, and/or haemodynamic crisis.

With respect to smoking, the patients were defined as smokers, ex-smokers, or nonsmokers. For those who smoked or had smoked, the duration of smoking, the average daily number smoked, the total (and age adjusted) number of cigarettes smoked, and time of their last cigarette was ascertained. The age adjusted number of cigarettes smoked was calculated as the total number divided by age minus 15 years, making the assumption that no patient had started smoking before 15 years of age. In order to determine the effect of age on our findings correlation coefficients were determined for the collected data with respect to age. In addition, data for age matched patients with focal ischaemic and senile sclerotic optic discs were compared. Patients were selected for the latter study on the basis of age alone and in a random fashion.

Statistical analysis for comparisons between the four groups involved an analysis of variance for continuous data (ANOVA with Duncan's correction for multiple comparisons; $\mathrm{p}<0.05$ ) and Pearson's $\chi^{2}$ or Fisher's exact test for categorical data. Fisher's exact test was used when an expected cell value was less than five. In order to determine the presence of any correlation between age and collected data Spearman's correlation test was used for categorical data and Pearson's correlation test for continuous data. Patients for the age matched part of the study were selected by a random process using only patients between the ages of 55 and 85 years. Student's $t$ test was used in the comparison of continuous data between two age matched groups of patients. For all tests a $p$ value of less than 0.05 was considered statistically significant. The statistical analysis was performed using SPSs 6.1 for Windows (Prentice Hall, NJ, USA). 
Table 1 Demographic patient/eye data for the four disc appearance groups

\begin{tabular}{|c|c|c|c|c|c|}
\hline & $\begin{array}{l}\text { Focal } \\
\text { ischaemic } \\
\text { (FI) }\end{array}$ & $\begin{array}{l}\text { Myopic } \\
\text { glaucomatous } \\
(M G)\end{array}$ & $\begin{array}{l}\text { Senile } \\
\text { sclerotic } \\
\text { (SS) }\end{array}$ & $\begin{array}{l}\text { Generalised } \\
\text { cup } \\
\text { enlargement } \\
(G E)\end{array}$ & p Value ${ }^{\star}$ \\
\hline Number & 38 & 37 & 24 & 24 & \\
\hline \multicolumn{6}{|l|}{ Diagnosis (n) } \\
\hline POAG & 26 & 24 & 19 & 19 & \\
\hline NTG & 8 & 12 & 5 & 0 & \\
\hline PXF & 3 & 1 & 0 & 2 & \\
\hline PDS & 1 & 0 & 0 & 3 & \\
\hline \multicolumn{6}{|l|}{ Eye $(\mathrm{n}(\%))$} \\
\hline Right & $23(60.5)$ & $21(56.8)$ & $15(62.5)$ & $9(37.5)$ & \\
\hline Left & $15(39.5)$ & $16(43.2)$ & $9(37.5)$ & $15(62.5)$ & ns \\
\hline \multicolumn{6}{|l|}{$\operatorname{Sex}(\mathrm{n}(\%))$} \\
\hline Male & $13(34.2)$ & $25(67.6)$ & $12(50.0)$ & $13(54.2)$ & $0.02 \dagger$ \\
\hline Female & $25(65.8)$ & $12(32.4)$ & $12(50.0)$ & $11(45.8)$ & $0.01 \ddagger$ \\
\hline Age (years) (mean $(\mathrm{SD}))$ & $64.8(13.0)$ & $54.8(11.0)$ & $75.6(8.8)$ & $63.5(11.1)$ & $<0.00001 \|$ \\
\hline \multicolumn{6}{|l|}{$\operatorname{Race}(\mathrm{n}(\%))$} \\
\hline White & $35(92.1)$ & $22(59.5)$ & $23(95.8)$ & $22(91.7)$ & \\
\hline Asian & $3(7.9)$ & $15(40.5) \S$ & $1(4.2)$ & $2(8.3)$ & $0.00001 \S$ \\
\hline Family history of glaucoma (n (\%)) & $16(42.1)$ & $15(40.5)$ & $11(45.8)$ & $13(54.2)$ & ns \\
\hline \multicolumn{6}{|l|}{ IOP $(\mathrm{mm} \mathrm{Hg})$ (mean (SD)) } \\
\hline Highest & $24.7(5.1)$ & $23.4(4.4)$ & $25.8(6.9)$ & $34.6(8.2)$ & $<0.000019$ \\
\hline Mean of 3 highest & $23.0(4.2)$ & $21.8(3.6)$ & $24.0(6.3)$ & $32.2(8.0)$ & $<0.000019$ \\
\hline Refraction (D) (mean (SD)) & $0.0(2.2)$ & $-5.9(2.5)$ & $-0.3(2.0)$ & $-0.2(2.5)$ & $<0.00001 \#$ \\
\hline Visual field defect (dB) (mean deviation) (mean (SD)) & $-9.5(4.9)$ & $-8.4(5.5)$ & $-6.2(4.0)$ & $-3.9(3.6)$ & $0.0001 \$$ \\
\hline
\end{tabular}

POAG = primary open angle glaucoma $\mathrm{NTG}=$ normal tension glaucoma; PXF = pseudoexfoliation syndrome; PDS = pigment dispersion syndrome; $\mathrm{ns}=$ no significant differences.

*Pearson's $\chi^{2}$ test for categorical data; analysis of variance (ANOVA) for continuous data with Duncan's correction for multiple comparisons $(\mathrm{p}<0.05)$.

†There were more males in the myopic glaucoma group in comparison with the other groups.

†There were more females in the focal ischaemic glaucoma group in comparison with the other groups.

$\|$ Patients with myopic glaucoma were younger than patients with each of the other types of glaucomatous discs.

Patients with senile sclerotic glaucoma were older than patients with each of the other types of glaucomatous discs.

$\$$ There were more Asian (Oriental) patients in the myopic glaucoma group in comparison with the other groups.

ๆBoth the highest recorded IOP and the mean of the highest three recorded IOPs were greater in the group of eyes with glaucoma associated with generalised enlargement of the optic disc cup in comparison with each of the other groups.

\#The degree of myopia in the group of eyes with myopic glaucoma was greater in comparison with each of the other groups.

\$The visual field mean deviation in eyes with myopic glaucoma was greater than in eyes with generalised cup enlargement glaucoma.

The visual field mean deviation in eyes with focal ischaemic glaucoma was greater than in eyes with senile sclerotic or generalised cup enlargement glaucoma.

\section{Results}

One hundred and twenty three patients with photographically pure focal ischaemic glaucoma $(n=38)$, myopic glaucoma $(n=37)$, senile sclerotic glaucoma $(n=24)$, and glaucoma with generalised enlargement of the optic cup $(n=24)$ met the study inclusion criteria. Demographic data for the patients and their study eye are listed in Table 1 . The vasospasm, systemic disease, and drug/smoking history data are listed in Tables 2, 3, and 4 respectively.

DEMOGRAPHY (TABLE 1)

The group of patients with myopic glaucoma were significantly younger, with a mean age of 55 years, than those with other optic disc appearances (range 64-76 years; $\mathrm{p}<0.00001$ ) and included more Asian/Oriental individuals $(40.5 \%$ versus $4.2 \%-8.3 \%$ in the other three groups; $p=0.00001)$. The group of patients with senile sclerotic glaucoma were significantly older, with a mean age of 76 years, than those with other optic disc appearances (range $55-65$ years; $p<0.00001)$. There was a significant excess of men in the myopic glaucoma group $(67.6 \%)$ and more women in the focal ischaemic group $(65.8 \%)$. The sex distribution was equal in both the groups of patients with senile sclerotic discs and generalised enlargement of the optic cup. The level of IOP, both as the highest recorded and the mean of the three highest recorded pressures, was significantly

Table 2 Vasospasm data for the four disc appearance groups

\begin{tabular}{|c|c|c|c|c|c|}
\hline & $\begin{array}{l}\text { Focal ischaemic } \\
\text { (FI) }\end{array}$ & $\begin{array}{l}\text { Myopic } \\
\text { glaucomatous (MG) }\end{array}$ & $\begin{array}{l}\text { Senile sclerotic } \\
(S S)\end{array}$ & $\begin{array}{l}\text { Generalised cup } \\
\text { enlargement }(G E)\end{array}$ & p Value* \\
\hline Number & 38 & 37 & 24 & 24 & \\
\hline Vasospasm (n (\%)) & $24(63.2) \dagger$ & $18(48.6)$ & $9(37.5)$ & $6(25.0) \ddagger$ & $\begin{array}{l}0.01 \dagger \\
0.02 \ddagger\end{array}$ \\
\hline Cold extremities (n (\%)) & $25(65.8) \S$ & $11(29.7)$ & $7(29.2)$ & $4(16.7) \|$ & $\begin{array}{l}0.015 \| \\
0.00003 \$\end{array}$ \\
\hline Migraine (n (\%)) & $12(31.6)$ & $7(18.9)$ & $2(8.3)$ & $3(12.5)$ & 0.029 \\
\hline Vasospastic score (SD) & $1.61(0.97)$ & $0.97(0.90)$ & $0.75(0.99)$ & $0.54(0.98)$ & $0.0001 \#$ \\
\hline
\end{tabular}

ns $=$ no significant differences.

^Pearson's $\chi^{2}$ tests for categorical data; analysis of variance (ANOVA) for continuous data with Duncan's correction for multiple comparisons $(\mathrm{p}<0.05)$.

tA peripheral vasospastic response was more common in the focal ischaemic group in comparison with the other groups.

$\ddagger$ A peripheral vasospastic response was less common in the group with generalised cup enlargement in comparison with the other groups.

\| The subjective complaint of cold extremities was more common in the group with focal ischaemic discs in comparison with the other groups.

$\$$ The subjective complaint of cold extremities was less common in the group with generalised cup enlargement in comparison with the other groups.

IMigraine was more common in the focal ischaemic group in comparison with the other groups.

\#The vasospastic score for the focal ischaemic group was higher than for each of the other groups. 
Table 3 Systemic disease data for the four disc appearance groups

\begin{tabular}{llllll}
\hline & $\begin{array}{l}\text { Focal ischaemic } \\
\text { (FI) }\end{array}$ & $\begin{array}{l}\text { Myopic } \\
\text { glaucomatous } \\
\text { (MG) }\end{array}$ & $\begin{array}{l}\text { Senile sclerotic } \\
\text { (SS) }\end{array}$ & $\begin{array}{l}\text { Generalised cup } \\
\text { enlargement } \\
\text { (GE) }\end{array}$ & $p$ Value* \\
\hline Number & 38 & 37 & 24 & 24 & $0.01 \dagger$ \\
Hypertension (n (\%)) & $6(15.8)$ & $5(13.5)$ & $10(41.7)$ & $5(20.8)$ & $0.02 \ddagger$ \\
Ischaemic heart disease (n (\%)) & $3(7.9)$ & $1(2.7)$ & $5(20.8)$ & $1(4.2)$ & $\mathrm{ns}$ \\
Diabetes (n (\%)) & $1(2.6)$ & $2(5.4)$ & $3(12.5)$ & $1(4.2)$ & $\mathrm{ns}$ \\
Cerebral ischaemic disease (n (\%)) & $2(5.3)$ & $1(2.7)$ & $2(8.3)$ & $1(4.2)$ & $\mathrm{ns}$ \\
Haemodynamic crisis (n (\%)) & $2(5.3)$ & $4(10.8)$ & $2(8.3)$ & 0 & 0.01 \\
Any cardiovascular disease (n (\%)) & $8(21.0)$ & $11(29.7)$ & $14(58.3)$ & $6(25.0)$ & $0.02 \|$ \\
CVS disease score (SD) & $0.37(0.88)$ & $0.35(0.59)$ & $0.92(0.97)$ & $0.33(0.64)$ & $2(8.3)$ \\
Thyroid disease (n (\%)) & $2(5.3)$ & 0 & $5(20.8)$ & & 0.015 \\
\hline
\end{tabular}

$\mathrm{ns}=$ no significant differences.

*Pearson's $\chi^{2}$ or Fisher's exact test for categorical data; analysis of variance (ANOVA) for continuous data with Duncan's correction for multiple comparisons $(\mathrm{p}<0.05)$.

†Hypertension was more common in the senile sclerotic group in comparison with the other groups.

$\ddagger$ Ischaemic heart disease was more common in the senile sclerotic group in comparison with the other groups.

|| The cardiovascular disease score was higher in the senile sclerotic group in comparison with the other groups.

\Thyroid disease was more common in the senile sclerotic group in comparison with the other groups.

greater in the group of eyes with generalised enlargement of the optic cup (highest recorded, $34.6 \mathrm{~mm} \mathrm{Hg}$ and mean of three highest, $32.2 \mathrm{~mm} \mathrm{Hg}$ ) compared with the other groups (highest recorded, $23.4-25.8 \mathrm{~mm} \mathrm{Hg}$ and mean of three highest, $21.8-24.0 \mathrm{~mm} \mathrm{Hg}$; $\mathrm{p}<0.00001)$. The visual field defects, in terms of mean deviation (MD), were greater $(p=0.0001)$ in the groups of eyes with focal ischaemic (mean $\mathrm{MD}=-9.5 \mathrm{~dB}$ ) or myopic glaucoma $(-8.4 \mathrm{~dB})$ in comparison with either senile sclerotic glaucoma $(-6.2 \mathrm{~dB})$ or that characterised by generalised cup enlargement $(-3.9 \mathrm{~dB})$. As expected, the group of eyes with myopic glaucoma (even though selected by disc appearance alone) had a significantly more myopic refraction with a mean value of $-5.9 \mathrm{D}$ in comparison with 0.0 to $-0.3 \mathrm{D}$ in the other three groups. There were no significant differences between the groups in relation to a family history with approximately $45 \%$ of all the patients having a known family history of glaucoma.

VASOSPASM (TABLE 2)

Both a peripheral vasospastic response to temperature change $(63 \%)$ and the subjective complaint of cold extremities (66\%) were significantly more common in the focal ischaemic group $(p=0.01$ and $p=0.00003$ respectively) and significantly less common in the group with generalised cup enlargement (25\%; $\mathrm{p}=0.02$ ) in comparison with the other groups. In addition, migraine was more prevalent in the focal ischaemic group (32\%) in compari- son with the other groups (8\% to $19 \%$; $\mathrm{p}=0.02)$. The overall mean vasospastic score for the focal ischaemic group (1.61) was significantly higher than for each of the other groups $(0.54$ to $0.97 ; p=0.0001)$. In addition, there was a tendency for the vasospastic variables to be more prevalent in the myopic glaucoma group but the differences were not statistically significant.

SYSTEMIC DISEASE (TABLE 3)

Hypertension and ischaemic heart disease were found to be more prevalent in the senile sclerotic group ( $42 \%$ and $21 \%$ respectively) in comparison with the other groups (13\% to $21 \% ; \mathrm{p}=0.01$ and $3 \%$ to $8 \% ; \mathrm{p}=0.02$, respectively). In addition, the occurrence of diabetes and cerebral ischaemic disease was more common in the senile sclerotic group but the differences were not statistically significant owing to the low overall prevalence of the conditions. However, the overall mean cardiovascular disease score was significantly higher in the senile sclerotic group ( 0.92 versus 0.33 to 0.37 in the other groups; $p=0.02)$. Thyroid disease (mainly hypothyroidism) was also found to be more prevalent in the senile sclerotic group $(21 \%$ versus 0 to $8 \%$ in the other three groups; $p=0.01)$. One of the patients in the focal ischaemic group had previously had hyperthyroidism, all other patients with previous thyroid disease had had hypothyroidism.

Table 4 Drug history and cigarette smoking data for the four disc appearance groups

\begin{tabular}{|c|c|c|c|c|c|}
\hline & $\begin{array}{l}\text { Focal } \\
\text { ischaemic } \\
\text { (FI) }\end{array}$ & $\begin{array}{l}\text { Myopic } \\
\text { glaucomatous } \\
\text { (MG) }\end{array}$ & $\begin{array}{l}\text { Senile } \\
\text { sclerotic (SS) }\end{array}$ & $\begin{array}{l}\text { Generalised } \\
\text { cup } \\
\text { enlargement } \\
(G E)\end{array}$ & p Value ${ }^{\star}$ \\
\hline Number & 38 & 37 & 24 & 24 & \\
\hline Vasoactive eye medication (n (\%)) & $24(63.2)$ & $20(54.1)$ & $14(58.3)$ & $14(58.3)$ & ns \\
\hline Vasoactive oral medication ( $(\%))$ & $6(15.8)$ & $4(10.8)$ & $12(50.0)$ & $5(20.8)$ & $0.0006 \dagger$ \\
\hline Aspirin (n (\%)) & $6(15.8)$ & $5(13.5)$ & $6(25.0)$ & $1(4.2)$ & ns \\
\hline Ex/smoker (n (\%)) & $18(47.3)$ & $12(32.4)$ & $11(45.8)$ & $15(62.5)$ & ns \\
\hline Smoking years (mean (SD)) & $8.5(11.8)$ & $4.5(9.2)$ & $12.2(15.5)$ & $14.6(16.7)$ & $0.02 \ddagger$ \\
\hline Cigarettes/day (mean (SD)) & $3.9(7.4)$ & $5.3(6.7)$ & $6.4(10.3)$ & $6.3(8.2)$ & ns \\
\hline Age adjusted number of cigarettes smoked (mean (SD)) & $1014(1633)$ & $786(1617)$ & $684(1290)$ & $713(1460)$ & ns \\
\hline
\end{tabular}

ns $=$ no significant differences.

^Pearson's $\chi^{2}$ or Fisher's exact test for categorical data; analysis of variance (ANOVA) for continuous data with Duncan's correction for multiple comparisons $(\mathrm{p}<0.05)$.

†Patients in the senile sclerotic group were taking more vasoactive systemic medications in comparison with the other groups.

$\ddagger$ Patients in the myopic glaucoma group had smoked for less years in comparison with those in either the senile sclerotic or generalised cup enlargement groups. 
Table 5 Age matched comparison between focal ischaemic and senile sclerotic groups

\begin{tabular}{|c|c|c|c|}
\hline & $\begin{array}{l}\text { Focal ischaemic } \\
\text { (FI) }\end{array}$ & $\begin{array}{l}\text { Senile sclerotic } \\
(S S)\end{array}$ & $p$ Value* \\
\hline $\mathrm{n}$ & 22 & 22 & \\
\hline Age (years) (mean (SD)) & $72.7(7.4)$ & $75.4(7.3)$ & ns \\
\hline \multicolumn{4}{|l|}{$\operatorname{Sex}(\mathrm{n}(\%))$} \\
\hline Male & $8(36.4)$ & $11(50)$ & \\
\hline Female & $14(63.6)$ & $11(50)$ & ns \\
\hline Hypertension (n (\%)) & $4(18.2)$ & $10(45.4)$ & $0.05 \dagger$ \\
\hline Ischaemic heart disease (n (\%)) & 0 & $5(22.7)$ & $0.02 \ddagger$ \\
\hline Diabetes (n (\%)) & 0 & $3(13.6)$ & ns \\
\hline Cerebral ischaemic disease (n (\%)) & $1(4.5)$ & $2(9.1)$ & ns \\
\hline CVS disease score (mean (SD)) & $0.27(0.55)$ & $1.00(0.98)$ & $0.004 \|$ \\
\hline Thyroid disease $(\mathrm{n}(\%))$ & $2(9.1)$ & $5(22.7)$ & ns \\
\hline Vasospasm (n (\%)) & $14(63.6)$ & $9(40.9)$ & ns \\
\hline Migraine (n (\%)) & $5(22.7)$ & $2(9.1)$ & ns \\
\hline Cold extremities (n (\%)) & $15(68.2)$ & $7(31.8)$ & $0.02 \S$ \\
\hline Vasospasm score (mean (SD)) & $1.55(0.96)$ & $0.82(1.00)$ & $0.02 \pi$ \\
\hline
\end{tabular}

ns $=$ no significant differences.

${ }^{\star}$ Pearson's $\chi^{2}$ or Fisher's exact test for categorical data; Student's t-test for continuous data.

†Hypertension was more prevalent in the senile sclerotic group in comparison with the age matched focal ischaemic group.

$\ddagger$ Ischaemic heart disease was more prevalent in the senile sclerotic group in comparison with the age matched focal ischaemic group.

$\|$ The cardiovascular disease score was greater for the senile sclerotic group in comparison with the age matched focal ischaemic group.

SCold extremities were more common in the focal ischaemic group in comparison with the age matched senile sclerotic group.

IThe vasospasm score was greater for the focal ischaemic group in comparison with the age matched senile sclerotic group.

DRUG AND SMOKING HISTORY (TABLE 4)

There was no significant difference between the groups with respect to the use of vasoactive ocular medications or aspirin but significantly more patients in the senile sclerotic group were using systemic vasoactive drugs (50\% versus $11 \%$ to $21 \%$ in the other groups; $\mathrm{p}=0.0006)$.

The number of smokers or ex-smokers was lowest for the myopic glaucoma group, although the difference in comparison with the other groups was not statistically significant. The mean duration of smoking was significantly lower for the myopic group (4.5 years versus 8.5 to 14.6 years; $p=0.02$ ) but since the mean age of patients in this group was lower than the other groups ( 55 years versus 64 to 76 years; $p<0.00001$ ) when an age adjusted determination of the number of cigarettes smoked was calculated there was no significant difference in the smoking habits between the groups.

\section{AGE EFFECTS}

Age was found to correlate with the occurrence of hypertension $(r=0.30, p=0.001)$ and ischaemic heart disease $(r=0.18, \mathrm{p}=0.05)$, the use of systemic vasoactive drugs $(r=0.37, \mathrm{p}<0.0001)$, the cardiovascular disease score $(r=0.31$, $\mathrm{p}<0.0001)$, thyroid disease $(r=0.25, \mathrm{p}=0.005)$, migraine $(-0.20, \mathrm{p}=0.02)$, and duration of smoking $(r=0.20, p=0.03)$. The use of vasoactive systemic drugs showed a strong correlation with the cardiovascular disease score $(r=0.77$, $\mathrm{p}<0.0001)$. Age was not correlated with vasospasm to temperature change, cold extremities, the vasospasm score, diabetes, haemodynamic crises, or cerebral ischaemic disease.

Since the mean age of patients in the senile sclerotic group (76 years) was greater than the other groups (55-65 years; $\mathrm{p}<0.00001$, see Table 1) and a number of systemic disease variables were correlated with age, a comparison was made between 22 patients with senile sclerotic discs and 22 age matched patients with focal ischaemic discs (Table 5). Even after matching for age, statistically significant differences were identified with respect to vasospasm and cardiovascular disease. Hypertension and ischaemic heart disease were more prevalent in the senile sclerotic group (45\% versus $18 \% ; \mathrm{p}=0.05$ and $23 \%$ versus $0 \%$; $\mathrm{p}=0.02$, respectively) and cold extremities were significantly more common in the focal ischaemic group $(68 \%$ versus $32 \% ; p=0.02)$. In addition, the overall mean vasospasm score was significantly higher for the focal ischaemic group (1.55 versus $0.82 ; \mathrm{p}=0.02)$ and the overall cardiovascular disease score was significantly higher for the senile sclerotic group (1.00 versus $0.27 ; \mathrm{p}=0.004$ ).

\section{COLD EXTREMITIES}

With the present cohort of 123 patients the subjective complaint of cold hands/feet showed a strong correlation with the calculated vasospasm score $(r=0.82, \mathrm{p}<0.0001)$ and significant correlations with the peripheral vasospastic response to temperature change $(r=0.51$, $\mathrm{p}<0.00051)$ and migraine $(r=0.25, \mathrm{p}=0.006)$.

\section{Discussion}

Chronic open angle glaucoma is a disease with a number of varying manifestations and quite marked variation in its course. There are many patients whose disease process is halted or markedly slowed down by the traditional and well established intervention of IOP reduction. There are other patients in whom an identical pressure reduction fails to stop the progression of existing visual field defects or the development of fresh losses in previously normally functioning areas. Furthermore, it is known that there are differences in the course of disease progression, being linear or curvilinear in some and quite episodic in others. ${ }^{40-42}$ It is generally agreed that in addition to IOP there must be other risk factors involved in the disease process. ${ }^{1-11}$ Race, increasing age, myopia, and a positive family history for glaucoma have been well documented as risk factors for development of open angle glaucoma. Studies of the vascular risk factors, however, have been more conflicting, perhaps a reflection of the fact that in only a proportion of patients with glaucoma do such factors play a significant role. Thus, it is important to identify subgroups of patients by factors that enable clinicians to better predict disease behaviour. The concept of differing optic disc appearances being indicative of distinct subsets of open angle glaucoma is not new and, although there may be many others, four optic disc appearances have been identified in previous reports. ${ }^{38}{ }^{43-46}$ Groups of patients with the different disc appearances have been studied and differences in their demographic characteristics, prevalence of potential risk factors for development or progression of the disease, and the pattern of their visual field loss have been identified. It is thought that the various disc appearances may correlate with various subtypes of glaucoma, the individual clusters of patients having similar disease with differing pathogenic mechanisms. In the present study 
some of the previously reported findings ${ }^{38} 44-46$ were confirmed with respect to vascular risk factors, patient demography, and general ocular findings.

Vasospasm has been proposed as one of the vascular risk factors with evidence provided by the animal studies of Anderson and co-workers, ${ }^{47}$ the demonstration by Phelps and co-workers that migraine occurs more commonly in patients with normal tension glaucoma ${ }^{26} 27$ and the demonstration by Flammer and co-workers that the vasospastic syndrome in older people often resembles normal tension glaucoma. ${ }^{28}{ }^{29}{ }^{31-33}$ Previously reported findings from our own department, using a principal component analysis on multiple standardised variables, showed that patients with primary open angle glaucoma, and not just those with normal tension glaucoma, could be split into two groups. ${ }^{17}$ The first group was predominantly vasospastic to cold and showed a linear relation between the highest recorded IOP and the amount of visual field loss. The second group appeared to be non-vasospastic to cold but had abnormalities in biochemical and haematological variables usually associated with vascular disease. In the latter group there was no relation between the highest IOP and the amount of field damage.

The importance of vasospasm may be a direct vasoconstrictive reduction in blood flow with resultant ischaemic damage or to impairment in the autoregulation of the retinal and optic nerve head circulation which is dependent on vasodilatation and pericyte contractility. ${ }^{48-50}$ Autoregulated vasodilatation may be intermittently or constantly impaired by the vasospasm. Any rises in IOP, falls in systemic blood pressure, or a combination of both would then produce circulatory impairment as a result of an inability of the circulation to adjust the blood flow to the changes in perfusion pressure at the optic nerve head. The vasospastic glaucoma patients might, therefore, be those in whom rises of IOP are most likely to result in initial damage or its progression. Furthermore, this hypothesis might explain the relation found between the highest IOP and the amount of damage in the vasospastic glaucoma cluster and its absence among the non-vasospastics. ${ }^{17}$

Conflicting results have been reported regarding the relation between vasospasm or migraine and open angle glaucoma. ${ }^{17} 26-345152$ The findings of the present study may help to explain these conflicting reports in the literature. By studying the four groups of glaucoma patients selected entirely by their distinctly differing disc appearances it was shown that vasospasm induced by cold, the presence of migraine or a history of cold extremities was significantly more frequent among the focal ischaemic group and to a lesser degree in the group with myopic glaucomatous disc appearances compared with the others. Of the three variables associated with vasospasm the history of cold extremities was the one most related to the focal ischaemic disc appearances in comparison with the other two.
The grouping together of all glaucoma patients is not helpful in identifying risk factors that only apply to a subgroup of the population. Studying glaucoma populations as a whole may result in the masking of factors that relate to only a subgroup of the patients. For example, a study would fail to identify vasospasm as a significant risk factor if, by chance, the population studied contained only a few patients with the focal ischaemic type of disc. Thus, in the present study and the earlier report from our department ${ }^{38}$ cold extremities, vasospasm to cold, and migraine were only identified as having significant associations after selecting a very specific subgroup of glaucoma patients based on the appearance of the optic nerve head.

The previous study from our department showed, in addition, that patients with a senile sclerotic disc appearance had a significantly higher prevalence of ischaemic heart disease and a "tendency" for a higher prevalence of hypertension. ${ }^{38}$ In the present study, the prevalence of both ischaemic heart disease and hypertension, even when allowing for age, were both "statistically" greater for this group of patients. An overall cardiovascular disease score taking hypertension, ischaemic heart disease, cerebral ischaemic disease, diabetes, and haemodynamic crisis into account confirmed that the group of patients with senile sclerotic disc appearances had a higher prevalence, or history, of generalised vascular disease. The significantly greater use of systemic vasoactive drugs by the patients with senile sclerotic discs was considered to relate to the increased prevalence of vascular disease within the group. In view of the uncertainty relating to any association between thyroid disease and glaucoma, ${ }^{53}$ together with the fact that hypothyroidism can be associated with the subjective complaint of feeling cold, the prevalence of thyroid disorders was considered. Although the absolute number of patients with a history of thyroid disease (mainly clinical hypothyroidism) was low it was of interest to find an increased prevalence in the group of patients with senile sclerotic discs, potential evidence that hypothyroidism may be a risk factor for the development of a subtype of glaucoma, perhaps due to an optic nerve head vasculopathy. ${ }^{53}$

As a result of present and previous findings, we believe that patients with the focal ischaemic, and probably myopic, type of glaucoma, who are vasospastic are likely to require significant IOP reduction. Determination of individual vasospasticity appears best by eliciting the subjective complaint of cold extremities or by feeling a cold limb. In these patients any agents aggravating vasospasm and the use of nicotine are probably best avoided. The use of vasodilators, however, including calcium channel blockers, may affect the process beneficially. ${ }^{32} 54$ The proportional decrease in IOP required remains unknown and longitudinal studies are required to determine whether the proposed hypothesis is actually true. In contrast, the main problem for patients with the senile sclerotic type of glaucoma is a 
generalised ischaemic one which is less likely to be IOP dependent - again only a longitudinal study could show whether this hypothesis is true. One of the problems relating to studies of patients with very "pure" disc appearances (such as purposely selected for the present study) is that they form only a small proportion of the patient population. In the present study only $7 \%$ of the optic discs examined were classified as pure examples, although $64 \%$ had a mixed appearance, while $27 \%$ were considered to have either a healthy appearance or advanced damage precluding secure group classification. However, patients with advanced damage or a mixed disc type may have had a pure optic disc appearance at one stage of their disease and furthermore, a mixed disc type may be the result of more than one concurrent, pathogenic mechanism. In many of the $64 \%$ patients with a mixed optic disc appearance two morphological components were often easily identified from the disc photographs. One of the commonest mixtures was the coexistence of focal tissue loss in association with generalised saucerisation and extensive peripapillary choroidal atrophy. This combination might suggest that the patient had a degree of vasospasticity but had also developed an underlying vasculopathy due to hypertensive disease and/or arteriosclerosis. The balance between the roles of such risk factors in the pathogenesis of glaucoma might explain why marked pressure reduction in some such individuals is beneficial, whereas in others it fails to halt visual field deterioration. If the hypothesis is true, when vasospasm (and resulting impairment of autoregulation) dominates over vasculopathy a marked reduction in IOP would be beneficial, in that it would lessen the effect of defective autoregulation. In contrast, when vasculopathy dominates over vasospasm, reduced IOP may have less influence on visual field preservation. If such risk factors and their influence on the disease process are verified by longitudinal studies, determining disc appearance of some $70 \%$, rather than just $7 \%$, of the glaucoma population would help to identify pathogenetic mechanisms with implications for both management and determination of disease prognosis.

In conclusion, the present study has provided further evidence for the existence of subgroups of open angle glaucoma patients. In addition to the assessment of IOP, vasospasm and cardiovascular diseases are important conditions to be considered in patients with glaucoma. The taking of a thorough history can help in determining the presence of risk factors other than the level of IOP and a careful clinical examination of the optic disc may provide additional information as to the subtype of the glaucoma. If these concepts are verified by future studies they may have important implications for the management of patients with glaucoma.

DCB was supported by the TFC Frost Trust, London

Each author states that he has no proprietary interest in any of the products mentioned in this article.
1 Drance SM, Sweeny VP, Morgan RW, et al. Studies of factors involved in the production of low-tension glaucoma. Arch Ophthalmol 1973;89:457-65.

2 Anderson DR. The posterior segment in glaucomatous eyes. In: Luetjen-Drecoll E, ed. Basic aspects in glaucoma research. Stuttgart: Schattauer-Verlag, 1982:167-90.

3 Hollows FC, Graham PA. Intra-ocular pressure, glaucoma and glaucoma suspects in a defined population. $\mathrm{Br} f \mathrm{Oph}-$ thalmol 1966;50:570-86.

4 Sommer A, Tielsch JM, Katz J, et al. Relationship between intraocular pressure and primary open angle glaucoma among white and black Americans. The Baltimore Eye among white and black Americans. The
Survey. Arch Ophthalmol 1991;109:1090-5.

5 Hart W Jr, Yablonski M, Kass MA, et al. Multivariate analysis of the risk of glaucomatous field loss. Arch Ophthalmol sis of the risk of glat

6 Quigley HA, Enger C, Katz J, et al. Risk factors for the development of glaucomatous visual field loss in ocular hypertension. Arch Ophthalmol 1994;112:644-9.

7 Wilson MR, Hertzmark E, Walker AM, et al. A case-contro study of risk factors in open angle glaucoma. Arch Ophthalmol 1987; 105:1066-71.

8 Shin DH, Becker B, Kolker AE. Family history in primary open-angle glaucoma. Arch Ophthalmol 1977;95:598-600.

9 Drance SM, Schulzer M, Douglas GR, et al. Use of discriminant analysis. II. Identification of persons with glaucomatous visual field defects. Arch Ophthalmol 1978; 96:1571-3.

10 Tielsch JM, Katz J, Sommer A, et al. Family history and risk of primary open angle glaucoma. The Baltimore Eye of primary open angle glaucoma. The

11 Stone EM, Fingert JH, Alward WLM, et al. Identification of a gene that causes primary open angle glaucoma. Science 1997;275:668-70

12 Spaeth GL. Fluorescein angiography: its contributions towards understanding the mechanisms of visual loss in glaucoma. Trans Am Ophthalmol Soc 1975;73:491-553.

13 Goldberg I, Hollows FC, Kass MA, et al. Systemic factors in patients with low-tension glaucoma. Br f Ophthalmol 1981; 65:56.

14 Demailly P, Cambien P, Plouin PF, et al. Do patients with low-tension glaucoma have particular cardiovascular characteristics? Ophthalmologica 1984;188:65-75.

15 Freyler H, Menapace R. Ist die Erblindung an Glaukom vermeidbar? Spektrum Augenheilkd 1988;2:121.

16 Carter CJ, Brooks DE, Doyle DL, et al. Investigations into a vascular etiology for low-tension glaucoma. Ophthalmology 1990;97:49-55.

17 Schulzer M, Drance SM, Carter CJ, et al. Biostatistical evidence for two distinct chronic open angle glaucoma populations. Br f Ophthalmol 1990;74:196-200.

18 Tielsch JM, Katz J, Sommer A, et al. Hypertension, perfusion pressure and primary open-angle glaucoma. A population-based assessment. Arch Ophthalmol 1995;113: 216-21.

19 Gramer E, Leydhecker W. Glaukom ohne Hochdruck. Klin Monatsbl Augenheilkd 1985;186:262-7.

20 Hayreh SS, Zimmerman MB, Podhajsky P, et al. Nocturnal arterial hypotension and its role in optic nerve head and arterial hypotension and its role in optic nerve head and 24 .

21 Graham SL, Drance SM, Wijsman K, et al. Ambulatory blood pressure monitoring in glaucoma. The nocturnal dip. Ophthalmology 1995;102:61-9.

22 Morgan RW, Drance SM. Chronic open-angle glaucoma and ocular hypertension. An epidemiological study. $\mathrm{Br} F$ Ophthalmol 1975;59:211-15.

23 Drance SM, Sweeney VP, Morgan RW, et al. Studies of factors involved in the production of low tension glaucoma. Arch Ophthalmol 1973;89:457-65.

24 Trope GE, Salinas SA, Glynn M. Blood viscosity in primary open-angle glaucoma. Can f Ophthalmol Vis Sci 1987;22. open-a.

25 Becker B. Diabetes mellitus and primary open-angle glaucoma. The XXVII Edward Jackson Memorial Lecture. Am $\mathcal{F}$ Ophthalmol 1971;71:1-16.

26 Corbett JJ, Phelps CD, Eslinger P, et al. The neurologic evaluation of patients with low-tension glaucoma. Invest Ophthalmol Vis Sci 1985;26:1101-4.

27 Phelps CD, Corbett JJ. Migraine and low-tension glaucoma. A case-control study. Invest Ophthalmol Vis Sci 1985;26: 1105-8.

28 Gasser P, Flammer J. Influence of vasospasm on visual function. Doc Ophthalmol 1987;66:3-18.

29 Flammer J, Guthauser U, Mahler M. Do ocular vasospasms help cause low-tension glaucoma? Doc Ophthalmol Proc Ser 1987;49:397-9.

30 Drance SM, Douglas GD, Wijsman K, et al. Response of blood flow to warm and cold in normal and low-tension glaucoma patients. Am f Ophthalmol 1988;105:35-9.

31 Guthauser U, Flammer J, Mahler F. The relationship between digital and ocular vasospasm. Graefes Arch Clin Exp Ophthalmol 1988;226:224-6.

32 Gasser P, Flammer J, Guthauser U, et al. Do vasospasms provoke ocular diseases? Angiology 1990;41:213-20.

33 Gasser P, Flammer J. Blood-cell velocity in the nailfold capillaries of patients with normal-tension and high-tension glaucoma. Am 7 Ophthalmol 1991;111:585-8.

34 Pillunat LE, Lang GK, Harris A. The visual response to increased ocular blood flow in normal pressure glaucoma. increased ocular blood flow in norm

35 Bornmyr S, Svensson H. Thermography and laser-Doppler flowmetry for monitoring changes in finger skin blood flow upon cigarette smoking. Clin Physiol 1991;11:135-41. 
36 Morgan RW, Drance SM. Chronic open-angle glaucoma and ocular hypertension: an epidemiological study. $B r \mathcal{F}$ Ophthalmol 1975;59:211-15.

37 Carel RS, Korczyn AD, Rock M, et al. Association between ocular pressure and certain health parameters. Ophthalmology 1984;91:311-14.

38 Nicolela MT, Drance SM. Various glaucomatous optic nerve appearances: clinical correlations. Ophthalmology 1996;103:640-9.

39 Nicolela MT, Walman BE, Buckley AR, et al. Various glaucomatous optic nerve appearances: a color Dopple imaging study of retrobulbar circulation. Ophthalmology 1996;103:1670-9.

40 Anderton SA, Coakes RC, Poinooswamy S, et al. The nature of visual loss in low tension glaucoma. In: Heijl A, Greve E, eds. Sixth international visual field symposium, 1984. eds. Sixth international visual field symposium

41 Mikelberg FS, Schulzer M, Drance SM, et al. The rate of Mikelberg FS, Schulzer M, Drance SM, et al. The rate of
progression of scotomas in glaucoma. Am $\mathfrak{f}$ Ophthalmo 1986;101:1-6.

42 McNaught AI, Crabb DP, Fitzke FW, et al. Modelling series of visual fields to detect progression in normal tension glaucoma. Graefes Arch Clin Exp Ophthalmol 1995;233: 750-5.

43 Geijssen HC, Greve EL. The spectrum of primary open angle glaucoma. I: Senile sclerotic glaucoma versus high tension glaucoma. Ophthalmic Surg 1987;18:207-13.

44 Geijssen HC, Greve EL. Focal ischaemic normal pressure glaucoma versus high pressure glaucoma. Doc Ophthalmol 1990;75:291-301.
45 Geijssen CH. Studies on normal pressure glaucoma. Amsterdam: Kugler, 1991.

46 Spaeth GL. A new classification of glaucoma including focal glaucoma. Surv Ophthalmol 1994;38:S9-17.

47 Anderson DR. The mechanisms of damage of the optic nerve. In: Kriegelstein G, Leydhecker W, eds. Glaucoma update. Heidelberg: Springer Verlag, 1983:89-93.

48 Anderson DR. Autoregulation in glaucoma. In: Drance S, ed. International symposium on glaucoma, ocular blood flow and drug treatment. Baltimore: Williams \& Wilkins, 1992:82-9.

49 Haefliger IO, Anderson DR. Blood flow regulation in the optic nerve head. In: Ritch $\mathrm{R}$, Shields M, Krupin T, eds. The glaucomas. St Louis: Mosby, 1995.

50 Anderson DR. Glaucoma, capillaries and pericytes. I. Blood flow regulation. Ophthalmologica 1996;210:257-62.

51 Usui T, Iwata K, Shirakashi M, et al. Prevalence of migraine in low-tension glaucoma and primary open-angle glaucoma in Japanese. Br F Ophthalmol 1991;75:224-6.

52 Klein BE, Klein R, Meuer SM, et al. Migraine headache and its association with open-angle glaucoma: the Beaver Dam Eye Study. Invest Ophthalmol Vis Sci 1993;34:3024-7.

53 Gillow JT, Shah P, O’Neill EC. Primary open angle glaucoma and hypothyroidism: chance or true association? Eye 1997;11:113-14.

54 Kitazawa Y, Shirai H, Go FJ. The effect of $\mathrm{Ca} 2+$-antagonist on visual field in low tension glaucoma. Graefes Arch Clin Exp Ophthalmol 1989;227:408-12. 